\title{
LITERATURAS SALVAJES: HACIA UNA LECTURA MESTIZA DE LUCIÉRNAGA PINDA
}

ASTRID ROMERO

Universidad Nacional de Río Negro

\section{LITERATURA Y COSMOVISIÓN: LA LECTURA DEL ORIGEN}

El estado actual de la poesía mapuche contemporánea nos ancla en un complejo territorio de delimitación de la frontera identitaria que propugna la necesidad de definir los términos de lectura y origen en el marco de ese espacio de por sí problemático. Así, la lectura entendida como un proceso dialéctico que contribuye a la construcción significante del objeto textual comporta en la literatura de Adriana Paredes un acto perturbador para el lector tanto mapuche como no mapuche, al constituirse en un espacio tensionado por los cruces entre la oralidad y la escritura, y los códigos castellano y mapuzungun.

Nombrada por Mabel García como "proceso de retradicionalización cultural", la práctica poetizante de la autora se define como "la observación y reflexión del pasado, reelaborándolo y situándolo en los lugares más propicios desde donde construir lo propio" (2012: 53). Desde ese espacio de construcción, la poeta mapuche huilliche Adriana Paredes, Luciérnaga Pinda, como ella misma se nombra, poetiza sobre la búsqueda de esa frontera iniciando una dialéctica del origen en su libro Üi, que comienza a prefigurarse desde el inicio con una introducción en la cual la poeta enuncia la pregunta "De por qué escribo", punto inicial de las fuerzas en tensión que atravesarán el texto; continuándose a lo largo del cuerpo poético formado por tres corpus: "Ralum I", "Awvn II" y "Bío-Bío III". 
En este marco, el término origen nos sitúa en un punto inmediatamente problemático desde su enunciación misma. El rastreo del origen como búsqueda de la genealogía implica pensar un determinado objeto en su devenir temporal, entendido como concepto lineal, e implica pensar ese mismo objeto como ente inmutable e incuestionable. Sin embargo, por la operación misma de esta dialéctica antes mencionada, sería también lícito pensar este problema desde una perspectiva einsteniana, desterrando para siempre el carácter lineal de la temporalidad. En este sentido, el origen podría pensarse como una entidad heterogénea, regida por variables relativas que permiten su abordaje como hecho "desdoblado", discontinuo. ¿Qué sería entonces el origen? Me permito arriesgar una posible definición: es el estallido en una presencia, la fluctuación de múltiples partículas que se organizan en una estructura significante. Desde esta perspectiva, el origen es también una destrucción, la aniquilación de una preexistencia en pos de la presencia, y en este punto es que la dimensión problemática adquiere su mayor densidad porque aunque esa destrucción alumbre un nacimiento no abandona su carácter destructivo. De esta manera, en el tercer poema del corpus "Ralum I", Adriana Paredes se sumerge de lleno en el problema del origen, el origen cantado, contado, que va "de boca a sueño a danza":

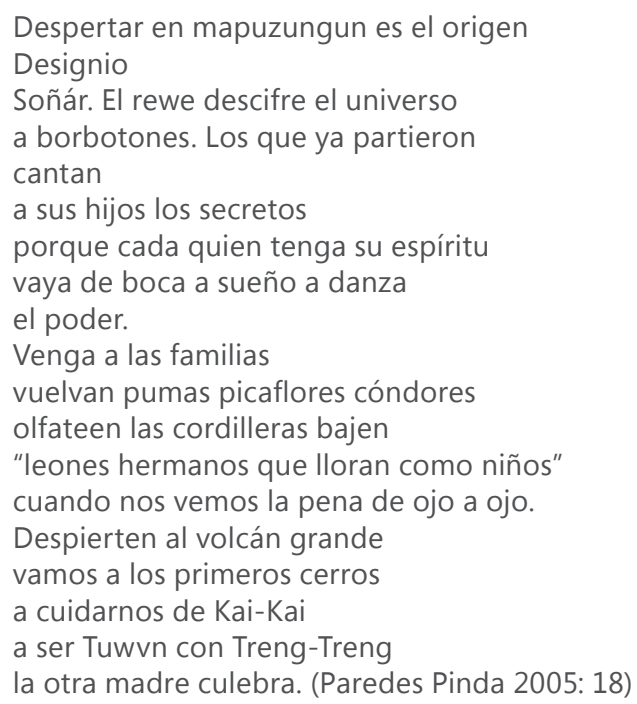

En su poesía despliega las certezas de los relatos míticos encarnados en las figuras de Kai-Kai y Treng-Treng ${ }^{1}$, en los que el mundo se canta tal y como en los tiempos primigenios de los hombres, cuando estos relatos tendían puentes a través de la voz entre el mundo físico y metafísico. Puentes que inician indefectiblemente un proceso de lenta destrucción con el advenimiento de La

\footnotetext{
${ }^{1}$ Estos personajes representan las fuerzas del mal y del bien respectivamente en los relatos mapuches antropogónicos. Para mayor información véase Espósito (2003: 256-257).
} 
Razón introducida en los pueblos originarios con la llegada del Huinca (hombre blanco).

De allí en adelante, la marca de la racionalidad va a provocar una enorme brecha con el pensamiento arcaico, mítico-mágico e iniciará el pasaje de la oralidad a la escritura, transformando las relaciones entre el mundo metafísico, su verbalización y, finalmente, el nexo entre aquellos y la materialidad de la escritura, tal como lo explicita Jacques Derrida:

En [el] logos el vínculo originario y esencial con la phoné nunca fue roto. [...] Tal como se la ha determinado más o menos implícitamente, la esencia de la phoné sería inmediatamente próxima de lo que en el "pensamiento" como logos tiene relación con el "sentido", lo produce, lo recibe, lo dice, lo "recoge". [...] entre el ser y el alma, las cosas y las afecciones, habría una relación de traducción o de significación natural; entre el alma y el logos una relación de simbolización convencional. Y la convención primera, la que se vincularía inmediatamente con el orden de la significación natural y universal, se produciría como lenguaje hablado. El lenguaje escrito fijaría convenciones que ligan entre sí otras convenciones. (Derrida 1971: 17)

Esa "marca" infringida a la cultura occidental se ha desbordado alcanzando otras culturas y sus discursos, dejando fuertemente impresa su huella, detentando su omnipresencia con gesto poderoso y desterrando al antiguo pensamiento mítico, pre-racional a un espacio salvaje, periférico, desde donde continúa fluctuando y bullendo en el imaginario colectivo de los pueblos originarios (nuevamente irrumpe ese vocablo "originario", estallido significante) y emerge por todos los intersticios posibles en un movimiento de búsqueda identitaria. En palabras de Roland Barthes "El mito no oculta nada y no pregona nada: deforma; el mito no es ni una mentira ni una confesión: es una inflexión [...]. Estamos en el principio mismo del mito: él transforma la historia en naturaleza" (1957: 222).

Partiendo de estos supuestos, intentaremos rastrear en la poesía de Adriana Paredes Pinda las huellas de un discurso mágico mítico considerado en tanto objeto en sí mismo, resultado más que de la occidentalización de la palabra mapuche, de un cruce, un mestizaje de dos lógicas mentales que prefiguran las marcas poéticas y alumbran una forma particular de apropiación de la palabra escrita, constituyendo el "hacerse oír" de la voz mapuche y que, al mismo tiempo, implican una lectura "incómoda" al trasladar ese espacio en conflicto a los lectores tanto mapuches como no mapuches.

Hablaremos de poética entonces y no de poesía porque nos volcaremos a ahondar en el sutil engranaje que habilita la creación poética de Adriana Paredes Pinda, en el sentido que Foucault ha delimitado para el campo de acción de la Arqueología, a propósito del estudio de los discursos:

La arqueología pretende definir no los pensamientos, las representaciones, las imágenes, los temas, las obsesiones que se ocultan o se manifiestan en los discursos, sino esos mismos discursos, esos discursos en tanto que prácticas que obedecen a unas reglas. No trata el discurso como documento, como signo de 
otra cosa, como elemento que debería ser transparente pero cuya opacidad importuna hay que atravesar con frecuencia para llegar, en fin, allí donde se mantiene en reserva, a la profundidad de lo esencial; se dirige al discurso en su volumen propio, a título de monumento. No es una disciplina interpretativa: no busca "otro discurso" más escondido. Se niega a ser "alegórica". (Foucault 1970: 233-234)

Tomado como objeto, el discurso poético no se sirve de la metáfora a fin de convocar el sentido más allá de la escritura, sino que es metáfora la materia, arcilla, que lo constituye. De esta manera la metáfora no es un medio para llegar a la inteligibilidad de un fin, es un fin en sí misma.

Así, este discurso-objeto monumental será nuestro punto de partida en el camino escritural que nos permita rastrear los ecos impresos de la voz mapuche.

\section{LÓGICA MÍTICA Y POÉTICA}

El mapudungún, la lengua de la tierra, es, de manera literal y ontológica, la tierra "que habla"; es la pérdida de la metáfora en su condición metafórica, en la irrupción, en el quiebre producido por el cruce no solo de lenguas sino también de culturas y géneros discursivos, que a la manera de un gran rompecabezas se rearma y se reafirma, en sentido político e identitario. Violentada por la llegada del hombre blanco, la literatura mapuche sufre una serie de transformaciones que han sido categorizadas por Hugo Carrasco Muñoz en "Rasgos identitarios de la poesía mapuche actual", trabajo en el que el autor marca los momentos del pasaje de la oralidad a la escritura experimentados por la literatura mapuche al distinguir "tres etapas: oralidad absoluta, oralidad inscrita y escritura propia" (2002: 83). La primera se corresponde con el periodo previo al contacto con el mundo occidental, la segunda con el de la transcripción y traducción de textos al castellano, y la tercera, que es la que nos ocupa, con el de la llamada por el autor "poesía etnocultural", que se define como "poesía en la que el mayor interés temático es la interacción de grupos étnicos y culturas distintas" (Carrasco 2002: 86). Aquí aparece lo que el autor denomina "texto de doble registro" para referirse a la confluencia de ambas lenguas en los textos. Es interesante advertir el carácter de "apropiación" otorgado por esta clasificación a la escrituralidad mapuche o, dicho de otra manera, cómo lo "otro" se torna "propio", ya que, paradójicamente, es un concepto como el que Derrida llamó "différance", el elemento constituyente de la identidad:

Tal es la cuestión: la alianza del habla y del ser en la palabra única, en el nombre al fin propio. Tal es la cuestión que se inscribe en la afirmación jugada de la différance. Se refiere a cada uno de los miembros de esta frase: "El ser/habla/en todas partes y siempre/a través de/toda/lengua". (Derrida 1968a: 20)

Desde el punto de vista occidental la estructura del pensamiento mítico comporta la idea de lo arcaico, lo pre-racional, propia de los pueblos "salvajes", propia del lenguaje oral, que no ha logrado elaborar un sistema de escritura. Esta 
concepción conlleva una fuerte carga negativa en torno a la noción de pensamiento mítico. Así, el mito se opone a lo que pertenece al orden de lo real, para devenir pura fábula.

En una línea de investigación completamente diferente, pero que nos proporciona un puente para pensar la cultura mapuche, Jean Pierre Vernant, en su obra Entre mito y política, nos advierte de la necesidad de prescindir de nuestros cuadros de pensamiento habituales para poder pensar el mito en la Grecia antigua (y que extrapolamos aquí a la cultura mapuche, salvando las enormes distancias), ya que "no existe entre la fabulación del mito y la autenticidad de lo divino que está implícito en la narración la incompatibilidad que estamos llevados a establecer" (2002: 101). No se trata de una cuestión menor: todo el enorme bagaje del pensamiento occidental descansa sobre la piedra fundamental del racionalismo cuyo dominio no se ha afirmado sino a costa de sufrimiento, tal como la poetisa denuncia:

... de que el lenguaje nos cambia la vida, hay que ver que sí, o tal vez la vida nos cambia el lenguaje, el cómo percibimos, atendemos a lo uno y a lo otro, el cómo nuestra memoria procesa, reencanta y se posesiona, cómo nos pensamos y pensamos los mundos y cómo los sonidos se trasuntan en aliento y palabra; en fin, algo se quebró en nuestros procesos cognitivos con la pérdida del idioma madre nuestro, el paso del che zugun al winca zugun no ha sido gratuito, nos ha costado sangre y esperanza. (Paredes Pinda 2005: 11)

Se trata entonces de asumir el desafío de desandar el camino de siglos de racionalismo para atribuir una frontera difusa entre mito y logos, y establecer la visión mítica como parámetro de análisis, en tanto constitutiva de un sistema de conocimiento. Nuevamente irrumpe la "différance":

Podremos, pues, llamar différance a esta discordia "activa", en movimiento, de fuerzas diferentes y de diferencias de fuerzas que opone Nietzsche a todo el sistema de la gramática metafísica en todas partes donde gobierna la cultura, la filosofía y la ciencia. (Derrida 1968a: 13)

Esta discordia de fuerzas hace tambalear entonces las bases fundacionales del viejo problema filosófico de la antinomia mito-logos dejándolo caer como un castillo de naipes, y a la hora de repartir nuevamente la baraja, la nueva estructura emerge con los mismos constituyentes resignificados: la poética mapuche pone en marcha sus engranajes y se sirve de la poesía para modelar sus saberes. En Crítica situada. El estado actual del arte y la poesía mapuche, sus autores señalan a propósito de esta cuestión:

Si se acepta la premisa de que la cultura mapuche sustenta sus patrones culturales en una visión mítico-simbólica y sacralizada del universo, los significados y significantes de los signos convencionalizados en la cultura surgen como condensadores semánticos de alto valor simbólico según atribución cultural de conocimiento colectivo y asimismo especializado. (García, Carrasco \& Contreras 2004: 21) 
Desde esta perspectiva, Adriana Paredes Pinda poetiza acerca de la visión mapuche del mundo, convirtiendo la poesía en el punto de reunión del mito y el logos, y sirviéndose de ella para reposicionarse en el mundo racional.

\title{
3. El universo poético de Luciérnaga Pinda
}

Luciérnaga Pinda se debate entre los límites de sus dos mundos y nos deja las marcas de esta contienda bajo la forma de una producción poética de considerable belleza. En su libro Üi, integrado por un prólogo-carta y tres cuerpos poéticos "Ralum I", "Awün II" y "Bío Bío III", se manifiestan las huellas de esta lucha y los trayectos donde aparecen las marcas de esta contienda.

De ellos se ocupa Paulo Huirimilla en "Üi: El puma azul de todos sus pewma de Adriana Paredes Pinda" (2009), en el que reseña, en primer lugar, "un metatexto cuya estructura es: epígrafe, poema y carta, donde de nuevo recurre a su kupalme e imágenes poéticas, para explicar su proceder mapuche, y de paso, bofetea los discursos de la cultura occidental". En segundo lugar, se despliegan los tres corpus poéticos: "Ralum I", en el que se denuncian los abusos contra la tierra y se inicia el despertar de la fuerza del pueblo mapuche; "Awün II", en el que se alude a las ceremonias y las autoridades religiosas que protegen al pueblo mapuche; y, por último, "Bio Bio III", que "viene siendo un canto a la resistencia de los mapuche-pewenche y una denuncia a los transnacionales" (Huirimilla 2009).

Es entonces en el interior del campo de batalla en el que esta contienda se despliega que nos interesa abordar el problema de la escrituralidad. A sabiendas del recorrido transitado por la literatura mapuche, nos encontramos con que el problema de la escrituralidad es, de alguna manera, un problema de identidad: "la consumación escritural es la resignación del üi", la pérdida del nombre propio.

\begin{abstract}
Algunos hablan de la "era del vacío", VACíO, VACíO, quizá esa es la razón por la cual escribo en delirio de mí y del pangui que no vendrá, el vacío de haber sido fracturados los pueblos invadidos y ultrajados, el vacío de haber sido rotos, quebrados, arrojados hacia dentro, sin retorno quizá; el vacío de haber perdido la lengua es haber ultrajado el aliento y eso no tiene parangón, no tiene compensación, porque no se trata únicamente de un conjunto de articulaciones o de un puñado de oxígeno, se trata de una pérdida irreparable, la muerte de un mundo no es un elemento de semiótica, no es un piuke mapuche y si para nacer de nuevo hay que romper un mundo, como dicen por ahí, ¿qué realidades se agazapan en la lengua violentada de nuestro pueblo? Y si como dicen por ahí, ¿habremos de nacer de nuevo en mapuzugun Febe, será que no hemos muerto y nuestra alma aún palpita a pesar de que nuestro idioma agoniza? Febe, Febe, sigue cantando que alegras mi corazón. (Paredes Pinda 2005: 11)
\end{abstract}

De una manera inversa entonces, la búsqueda de la identidad halla sentido en una vuelta a la oralidad, pero ¿es posible recuperar el fluir de la palabra en la escritura? $\mathrm{O}$, dicho de otro modo, ¿puede pensarse en la escritura como un afuera de la palabra? Derrida afirma al respecto que "el horizonte del saber absoluto es la borradura de la escritura en el logos, la reasunción de la huella en 
la parusía, la reapropiación de la diferencia, la realización de [...] la metafísica de lo propio" (1971: 35).

Estamos entonces ante un falso problema, ya que la escritura trasciende en este punto la concepción saussuriana de mera transcripción para devenir en sí misma sistema identitario: texto/territorio-desterritorializado, la retirada metafórica que Derrida reseña:

Esa palabra [retirada] me viene impuesta por razones económicas (ley del oikos y del idioma de nuevo), teniendo en cuenta, o intentándolo, capacidades de traducción o de captura o de captación traductora, de traducción o traslación en el sentido tradicional e ideal: traslado de un significado intacto al vehículo de otra lengua de otra patria o matria; o también en el sentido más inquietante y más violento de una captura captadora, seductora y transformadora (más o menos regulada y fiel, pero, ¿cuál es entonces la ley de esta fidelidad violenta?) de una lengua, de un discurso y de un texto, por parte de otro discurso, de otra lengua y de otro texto que pueden al mismo tiempo como va a ser aquí el caso, violar en el mismo gesto su propia lengua materna en el momento de importar a ella y de exportar de ella el máximum de energía y de información. (Derrida 1968b: 12)

Y es precisamente en este movimiento de inversión, de traslado de una "patria o matria" lingüística a otra, pero conservando los sentidos más caros a su identidad, que Adriana Paredes Pinda inscribe su poesía. La poesía es huella, canto y conjuro: es la presencia y la reapropiación de la diferencia de la que Derrida nos habla; y la lengua, merced de esta operación, una revelación:

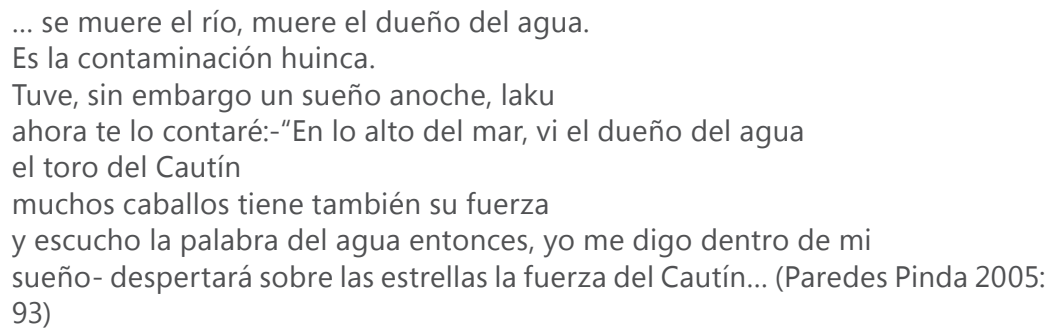

La huella escritural subvierte su propio sistema con la irrupción de la voz mapuche y se resignifica, en una operación que la torna en material identitario. Es una voz a la vez plural y subjetiva, movimiento de búsqueda identitario plasmado por la voz poética de Luciérnaga Pinda, pero también del pueblo mapuche en su conjunto, habilitado por un sistema de pensamiento que determina los mecanismos poéticos: "Es necesario reiterar que la metáfora que representa la poesía, considera esta como un micromundo que a su vez representa la voz de la sociedad indígena ancestral trasplantada al mundo winka de hoy" (Carrasco 2002: 93).

En su poética, Pinda cristaliza los mecanismos cognoscitivos mapuches: el rewe, sueño revelador, lee los designios universales que se transmiten de padres 
a hijos (voz indígena ancestral) y este conocimiento es poder. Poder que se apropia de la escritura quebrando la lengua con la voz mapuche y afirmándose en su huella. De esta manera, la pluralidad trasciende la materia textual y la escritura busca el origen.

\section{IDENTIDAD Y TRANSTEXTUALIDADES: LECTURAS MESTIZAS}

El lugar del lector se sitúa entonces en un abismo en el que cae por las heridas en la escritura y que violentan su lectura, lo trasladan de la comodidad de la norma hacia la incertidumbre de las voces que hablan y callan.

En una cultura desmembrada y negada por la racionalidad occidental, relegada al silencio y condenada al olvido, la poesía se erige como un camino de resistencia y recuperación en un proceso de constante transformación de la voz textual. Y el lector asiste a la contienda situado de repente en el centro del campo de batalla, donde es obligado a leer desde la incomodidad y la interpelación.

La poesía enfrenta los mundos del mito y del logos y los obliga a dirimir sus diferencias conjurando su presencia en la escritura en tanto metáfora desmetaforizada, aunque alberga aún en su seno la tensión de las contradicciones tal como lo vislumbra Adriana Paredes Pinda:

La cultura escritural olvidada de su propia memoria de piel, dominante y ambiciosa, intenta escribirse a sí misma (será que no puede con su soledad) y se enamora del oro que para los otros es sol, se enamora del árbol que para los otros es rewe, se enamora el Amazonas y la asesina desde el cielo y entonces busca la Ciudad de los Césares, solo para comérsela mejor; levanta sus imperios cognitivos, nos arranca la lengua y el aliento, reinventa la selva, el mar, la cordillera, todo lo nombra nuevamente, luego el "Ül" ya no significa, ya no respira, huye el nombre a los montes; la cultura escritural vomita soledad, mientras los kuifikeche yem nos cantan que en este mundo y en el otro no hay solos; la cultura escritural nos convierte en desolados y desoladas, nos hace herederos de su imperialismo discursivo de su poder simbólico y nos desarmamos, nos filosofamos, nos hermeneuticamos por todos lados, nos semantizamos, nos construimos y reconstruimos socialmente, sabemos que sabemos (tanto que no sabemos) y el mundo se hace de lo que decimos; nos confundimos todas esas tentadoras escaramuzas huincas; de la caza huinca; ¿cómo ver que en el wall y el wallontu mapu no hay soledad?, sentir el cuanto en la sangre ¿somos cuanto dicen hoy los científicos eminentes?, ya los científicos eminentes, ya lo sabían los chacha pues, que somos partículas fugaces de eternidad visible (al GONZALO sí le creerían, no ve que dice García Márquez que dijo el glotón de Neruda en Los cuentos peregrinos que solo la poesía es clarividente; ven qué ambiciosa es la cultura escritural. Si los abuelos sentían que en el vientre fluye el río, el remedio y la enfermedad, todo en un solo aliento. La cultura escritural es ciega, las estrellas siguen hablando, solo que la escrituralidad desde la cual y en la cual pensamos nos impide ver cuán vivas están, chacha. (Paredes Pinda 2005: 10)

Sin embargo, la huella escritural invade con la presencia y ocupa los espacios, desborda sentidos y significantes y viceversa: es invadida y ocupada, y en este sentido se transfigura en el terreno de la posibilidad. La muerte de la lengua 
mapuche a manos de la escrituralidad no es más que la resurrección de su voz: "para tejer el metawe del origen / que se cantó en azul. La piel / del mapuche tiene la escritura" (Paredes Pinda 2005: 30).

A propósito del pensamiento pre-racional de la cultura occidental señala Vernant, citando a su vez a Ruth Padel, que la metáfora no es solo una operación lingüística que pone en relación dos universos opuestos, sino que "lo metafórico en esos documentos debe ser tomado textualmente, como una manera no de decir, sino de pensar" (2002: 230).

Hay en el relato poético el atisbo de una construcción de la verdad, de la verdad del mundo como fusión entre la naturaleza y el hombre, la fuerza divina y la humana, que se manifiesta más allá del gesto singular de la poetisa, la trasciende a ella misma inaugurando un gesto enunciativo plural, que al mismo tiempo interpela fuertemente al lector. La poética mapuche se erige como punto intersticial en el cual el pensamiento mítico inflige una herida, una brecha que permite a los poetas mapuches pensarse y resignificarse en un sentido identitario que constituye a la vez un gesto político y que instaura la puesta en abismo del lector.

El territorio escritural, patria o matria del lector, se altera, se subvierte, y el caos convoca el origen. Las lecturas mestizas comportan un acto en permanente tensión: el origen es la llegada y el punto de partida, la inauguración de la presencia.

\section{OBRAS CITADAS}

Barthes, Roland (1957): "El mito, hoy". En: Mitologías. Buenos Aires, Siglo xxı.

Carrasco Muñoz, Hugo (2002): "Rasgos identitarios de la poesía mapuche actual". En: Revista Chilena de Literatura, n. ${ }^{\circ} 61$, pp. 83-110. Disponible en <http://www.revistas. uchile.cl/index.php/RCL/article/view/1672>. Última visita: 26.04.2014.

Derrida, Jacques (1971): De la gramatología. México, Siglo xxı.

(1968a): "La Différance". En: <http://www.jacquesderrida.com.ar/textos/la_ differance.htm>. Última visita: 26.04.2014.

(1968b): "La retirada de la metáfora". En: <http://www.jacquesderrida.com.ar/ textos/metafora.htm>. Última visita: 26.04.2014.

Espósito, María (2003): Diccionario mapuche. Personajes de la mitología. Toponimia indígena de la Patagonia. Nombre propios del pueblo mapuche. Leyendas. Buenos Aires, Guadal.

Foucault, Michel (1970): "Historia de las ideas". En: La arqueología del saber. México, Siglo XXI.

García Barrera, Mabel, Carrasco Muñoz, Hugo, y Contreras Hauser, Verónica (2005): Crítica situada. El estado actual del arte y la poesía Mapuche. Temuco (Chile), Florencia.

García Barrera, Mabel (2012): "El proceso de retradicionalización cultural en la poesía mapuche actual: Üi de Adriana Paredes Pinda". En: Revista Chilena de Literatura, n. ${ }^{\circ}$ 81, pp. 51-68. Disponible en <http://www.revistaliteratura.uchile.cl/index.php/RCL/ article/viewArticle/18723/29810>. Última visita: 26.04.2014. 
Huirimilla, Paulo (2009): "Üi: El puma azul de todos su pewma de Adriana Paredes Pinda". En: <http://letras.s5.com/ph100409.html>. Última visita: 26.04.2014.

(2005): "Etnopoesía y poética intercultural en la cosmovisión mapuche". En: <http:// www.letras.s5.com/pw1407071.pdf>. Última visita: 26.04.2014.

Moraga García, Fernanda (2006): "Adriana Pinda y el habla escrita de la ajenidad: Relámpago". En: Revista Alpha, n.23, pp. 117-136.

(2008): "(Des)tejiendo identidades". En: Revista Hispánica Internacional de Análisis Literario y Cultural, n. ${ }^{\circ} 74$, pp. 123-142.

(2012): "Políticas del sujeto y saberes situados en la poesía de mujeres mapuche contemporáneas". En: Ínsula. Revista de letras y ciencias humanas, n 791, pp. 15-19. (2009): "A propósito de la 'diferencia': poesía de mujeres mapuche". En: Revista Chilena de Literatura, n. ${ }^{\circ}$ 74, pp. 225-239. Disponible en <http://www.scielo.cl/pdf/ rchilite/n74/art11.pdf>. Última visita: 26.04.2014.

Paredes Pinda, Adriana (2005): Üi. Santiago de Chile, Lom Ediciones.

Rodríguez Monarca, Claudia (2005): "Weupüfes y machis: canon, género y escritura en la poesía actual mapuche". En: Estudios Filológicos, n. ${ }^{\circ}$ 40, pp. 151-163.

Vernant, Jean-Pierre (2002): Entre mito y política. México, Fondo de Cultura Económica. 